\title{
DIREITO E RELIGIÃO: APROXIMAÇÃO COM VISTAS AO ESTUDO DO TERCEIRO MANDAMENTO NOS PREÂMBULOS CONSTITUCIONAIS
}

Marcelo Coelho Almeida*

\begin{tabular}{l|l}
\hline RECEBIDO EM: & 27.8 .2020 \\
\hline APROVADO EM: & CONVIDADO \\
\hline
\end{tabular}

* Doutorando em Educação, Arte e História da Cultura da Universidade Presbiteriana Mackenzie(UPM), mestre em Ciências da Religião pela mesma instituição, especialista em Estado Constitucional e Liberdade Religiosa pela UPM e pela Associação Nacional de Juristas Evangélicos (Anajure), em parceria com a Ius Gentium Conimbrigae da Universidade de Coimbra (Portugal) e o Regent Park College da Universidade de Oxford (Reino Unido), e bacharel em Teologia pelo Seminário Presbiteriano do Sul (SPS) e em Psicologia e Formação de Psicólogo pela UPM. Professor nos cursos de Direito e Psicologia da UPM. E-mail: marcelo.capelao@mackenzie.br 
- MARCELO COELHO ALMEIDA

- RESUMO: A presente pesquisa pretende justificar o estudo do terceiro mandamento nos preâmbulos constitucionais apresentando-o como campo de aproximação entre o direito e a religião. Esses temas são analisados a partir de três enfoques: histórico, mormente na história brasileira desde o descobrimento; prático, em que se constata um número elevado de ações judiciais que têm como pano de fundo o tema da religião; e, por fim, especulativo, no qual se poderá incluir o estudo do terceiro mandamento nos preâmbulos, pois trata-se de análise de textos canônicos que exigem a solução do problema hermenêutico em ambas as áreas do saber: direito e religião.

- PAlAVRAS-chave: Direito e religião; Decálogo; preâmbulo.

\section{LAW AND RELIGION: APPROACH TOWARD THE THIRD} COMMANDMENT STUDY IN CONSTITUTIONAL PREAMBLES

- ABSTRACT: The present research intends to explain the study of the third commandment in the constitutional preambles presenting it as a field of approximation between law and religion. These themes are analyzed from three approaches. These are the historical focuses, especially in Brazilian history since its discovery; there is also the practical approach in which there is a high number of lawsuits that have as background the theme of religion; and finally the speculative approach in which the study of the third commandment may be included in the preambles, because it deals with the analysis of canonical texts, and requires the solution of the hermeneutical problem in both the areas of knowledge, law and religion.

- KEywords: Law and religion; Decalogue; preamble.

\section{Introdução}

O presente texto procura analisar a validade do estudo do terceiro mandamento da tradição judaico-cristã como campo legítimo de estudo dos preâmbulos constitucionais, justificado epistemologicamente como uma das muitas aproximações entre os temas de direito e religião. 
DIREITO E RELIGIÃO: APROXIMACÃO COM VISTAS AO ESTUDO DO TERCEIRO MANDAMENTO NOS PREÂMBULOS CONSTITUCIONAIS

A fim de preparar o leitor para análises específicas do terceiro mandamento e dos preâmbulos constitucionais, esta pesquisa tratará de explorar inicialmente a aproximação entre direito e religião. Com isso, o autor procura ressaltar a importância e a relevância acadêmica do tema envolvendo o uso do nome de Deus nos textos preambulares, pois é sabido que, no contexto de pesquisas acadêmicas feitas anteriormente, tanto por juristas quanto por teólogos, o assunto direito e religião ocupa um espaço de louvável destaque. Essa relevância se dá no âmbito do direito, no sentido da discussão teórica com a contribuição da teologia para instrumentalizar os juristas e dar-lhes informações que os subsidiem em sua tarefa. Essa contribuição pode consistir em proferimentos de decisões, ou acórdãos no caso de um magistrado ${ }^{1}$, estar relacionada ao campo da argumentação de defesa ou de contestação por parte de um(a) advogado(a) ou até mesmo ter o propósito de instrumentalizar promotores do Ministério Público ou demais agentes do direito para que possam ampliar seus olhares sobre o tema da religião e assim estar mais bem fundamentados ${ }^{2}$.

Ora, se, em apenas quatro anos após a promulgação da Constituição Federal de 1988, já havia o questionamento e uma ação judicial (Ação Direta de Inconstitucionalidade - ADI - n. 2076) requerendo a impugnação de uma Constituição Estadual (no caso a do estado do Acre). E o pano de fundo desse caso refere-se à presença ou ausência do nome de Deus no preâmbulo, o que foi julgado e negado pelo plenário do Supremo Tribunal Federal (STF) como uma questão que, nas palavras do relator ministro Carlos Velloso "reflete simplesmente um sentimento religioso" (grifo nosso) ${ }^{3}$. Portanto, estão límpidas e claras a necessidade e a relevância do tema da presente pesquisa, tanto no quesito científico/acadêmico quanto na prática e na aplicação em decisões judiciais. E, dentre os inúmeros casos nos quais os temas direito e religião são aproximados, este da

1 Como exemplo dessa necessidade de maior conhecimento de religião por parte dos magistrados, ver o caso do juiz da $17^{\text {a }}$ Vara de Fazenda Federal, Eugênio Rosa de Araújo, que voltou atrás em uma decisão anterior em uma ação que envolvia exposições de vídeos no canal de internet YouTube que seriam ofensivos à religião afro-brasileiras. Na decisão inicial e equivocada, o juiz escreveu que "manifestações religiosas afro-brasileira não se constituem religião".

2 Há o caso de impugnação da Constituição do Estado do Acre, pretendida em Ação Direta de Inconstitucionalidade (ADI n. 2076) pelo Partido Social Liberal (PSL) finalizada em 15 de agosto de 2012 no Supremo Tribunal Federal. A ação pretendia salvaguardar a Constituição Federal 1988 em cujo preâmbulo está a expressão "Sob a proteção de Deus", uma vez que apenas no texto da Constituição do Estado do Acre não havia a mesma expressão. Dessa forma, o PSL argumentou que, na Assembleia Constituinte de 1988, a tentativa de supressão da referida expressão fora derrotada. Já o voto do relator ministro Carlos Velloso dizia que o preâmbulo não tem força normativa e que na Constituição acreana todos os princípios democráticos são observados e igualmente a soberania popular, não ferindo a correlação com a Constituição Federal. Concluía o relator que a Constituição acreana "só não invoca a proteção de Deus que, posta no preâmbulo da Constituição Federal, reflete simplesmente um sentimento religioso”. 
Constituição do Acre sobre o nome de Deus no preâmbulo é um dos mais apropriados para justificar a pertinência desta pesquisa, porque falar sobre o uso adequado ou não do nome de Deus remete tanto o pesquisador do direito constitucional ao tema da religião quanto o teólogo ao estudo do conteúdo do terceiro mandamento e do Decálogo. Eis o que diz esse mandamento: "Não tomarás no nome do Senhor, teu Deus, em vão, porque o Senhor não terá por inocente o que tomar o seu nome em vão.” (Êxodo 20.7).

\section{Direito e religião: aproximações inequívocas no contexto brasileiro}

Há vários enfoques pelos quais constatamos, inexoravelmente, a aproximação entre direito e religião.

Quando se utiliza o enfoque histórico brasileiro, ver-se-ão as questões que envolvem o início da colonização brasileira e a aproximação, talvez jamais inseparável, dos temas direito público e religião. Quando Pedro Álvares Cabral aportou na Ilha, logo batizada de Ilha de Vera Cruz, ordenou a celebração, em 26 de abril de 1500, de uma missa como ato de "posse" da conquista da nova terra. Essa missa foi oficiada por frei Henrique Soares de Coimbra, superior dos franciscanos missionários que compunham a frota cabralina. Portanto, o ato cerimonial de instalação na terra recém-conquistada é legitimado com uma cerimônia religiosa. No livro bíblico do Gênesis ${ }^{4}$, Abraão, chamado pelo jornalista Bruce Feiler (1998) $)^{5}$ de o pai das três grandes religiões monoteístas, realizou o mesmo ato que deu origem a essa prática religiosa de "levantar um Altar ao Senhor”.

Veja-se também o processo de catequização dos índios por parte do padre Anchieta, que, ao fazê-lo, estabelece assim uma ideia de hegemonia e domínio em terras tupiniquins da religião cristã trazida do além-mar sob os critérios doutrinários de Roma que passaria a ditar as regras do Brasil por todos os longos e extensos anos seguintes, quiçá em alguns casos até nos dias de hoje. Como exemplo, tome-se o fato de que ainda no Império, mesmo separado por mais de 300 anos do chamado descobrimento do Brasil, encontra-se, no caput da Constituição do Império de 1824, a frase: "EM NOME DA

4 “Assim, Abrão desarmou o seu acampamento e foi morar perto das árvores sagradas de Manre, na cidade de Hebrom. Eali Abrão construiu um altar para Deus, o SENHOR" (Gênesis 13.18).

5 Jornalista do The New York Times, Feiler (1998) faz na obra Abraão: uma jornada ao coração de três religiões um excurso sobre os aspectos sociológicos acerca da influência de Abrão, este Pai comum das três grandes religiões monoteístas: judaísmo, cristianismo e islamismo. 
SANTÍSSIMA TRINDADE”. E no primeiro capítulo dessa mesma Constituição, art. 5, consta o seguinte: “A Religião Catholica Apostolica Romana continuará a ser a Religião do Império. Todas as outras Religiões serão permitidas com seu culto domestico, ou particular em casas para isso destinadas, sem fórma alguma exterior do Templo"6. $\mathrm{O}$ que se nota é a influência total daqueles atos religiosos na instalação da nova morada e sua subsequente e presentíssima influência normativa e cultural; uma total obediência aos ditames católicos romanos, inclusive com o aspecto restritivo a outras formas religiosas de expressão, de manifestação e de culto.

Segundo o Dr. Arnaldo Godoy, em sua exposição no Superior Tribunal de Justiça, em congresso realizado pela Associação Nacional dos Juristas Evangélicos (Anajure), em março de 2016, como resultado da catequização feita pelo padre José de Anchieta, o país passou até mesmo a adotar uma compreensão difusa entre crime e pecado, na qual não era possível identificar com clareza a diferença entre ambos.

Outro exemplo: na criação do serviço religioso das Forças Armadas, o domínio histórico da religião católica romana e sua força em questões de Estado e governo ficaram igualmente claros. Este autor, em pesquisa anterior sobre o tema, assim apresentou fato curioso que mostra essa influência da religião católica apostólica romana no Estado brasileiro:

Com a finalidade de atender à Primeira Divisão de Infantaria Expedicionária, foi criado um "Serviço de Assistência Religiosa” (SAR/FEB), através do Decreto-Lei no 5.573 de 26 de maio de 1944. Observe-se o episódio inusitado a partir do qual isso ocorreu. Em 1944, relatos orais dão conta que, após o desfile dos expedicionários que partiriam para Itália, o presidente Getúlio Vargas perguntou ao cardeal do Rio de Janeiro, Dom Jaime de Barros Câmara, qual era a sua opinião sobre o desfile. $\mathrm{O}$ cardeal respondeu que muito o apreciara, mas que faltava alguma coisa. $\mathrm{O}$ presidente indagou sobre o que estaria faltando, ao que o cardeal respondeu: “Os Capelães para dar a assistência ao soldado no campo de batalha” (apud MACEDO, 1994, p. 57). Getúlio Vargas se comprometeu, ali mesmo, a suprir tal deficiência e o Decreto-Lei no 5.573 , anteriormente citado, foi editado dias depois (ALMEIDA, 2006).

Após esse decreto-lei sob Getúlio Vargas, foram incorporados à tropa da Força Expedicionária Brasileira (FEB) e enviados para a Itália 30 padres católicos e dois pas-

6 Disponível em: https://www.planalto.gov.br/ccivil_03/constituicao/constituicao24.htm. Acesso em: 15 abr. 2020. 
tores evangélicos. Note o leitor o fato de que esse ocorrido se dá em 1944, portanto já havia se instituído o Estado laico pela Constituição de 1891, em que o nome de Deus não aparece, e duas outras constituições brasileiras já haviam sido promulgadas após esta, a de 1824, em cujo preâmbulo se utilizou a expressão “pondo confiança em Deus”. Mas a Constituição Polaca de 1937, que, entre outros aspectos, procurava legitimar ideais autoritários e totalitários, como vinha mostrando a prática do segundo governo de Vargas, tratou de suprimir novamente o nome de Deus do seu conteúdo preambular. Todavia, mesmo assim, em um Estado cada vez mais afastado da religião, uma decisão notadamente favorável à precedência da Igreja Católica sobre quaisquer outras religiões é tomada pelo mandatário Getúlio Vargas.

Enão apenas isso, pois um bom observador há de perceber a influência da religião em inúmeros outros casos no Brasil, sejam eles no âmbito do direito ou não. Este autor acredita que tal influência é, ainda hoje, resultado daqueles primórdios catequizantes.

Ao citar apenas um exemplo, note o leitor que as cerimônias oficiais de transmissão da faixa presidencial no Palácio do Planalto, até os dias de hoje, sempre são acompanhadas por um arcebispo da Igreja Católica Apostólica Romana.

Após breve análise de aspectos históricos, passamos agora a considerar, na junção dos temas direito e religião, os aspectos de aplicação prática do tema direito e religião no ambiente jurídico dos tribunais brasileiros, nos quais há registros de inúmeras ações judiciais cujos temas têm fundo ou motivação religiosos. E isso em diversas categorias, como na área tributária, no direito trabalhista, nas ações que ensejam perda de bens ou exploração financeira, no direito político, em que se veem vários casos de abuso de poder religioso, votos de cabrestos em igreja, políticos e até partidos políticos dirigidos por líderes de alguma denominação tal, e assim por diante ${ }^{7}$.

Contudo, os casos práticos de maior vulto nos tribunais brasileiros são os que estão no âmbito da relação Igreja e Estado. E nesse ponto há grande semelhança do que acontece no Brasil com o que vemos com frequência em vários países do mundo. Machado (2013) apresenta sobejo número de casos no direito internacional que abarcam

7 Sobre esse tema da religião e sua influência na política brasileira, há um vasto campo já pesquisado anteriormente. Dois autores podem ser consultados para aprofundamento do tema: Robinson Cavalcanti e Paul Freston. O primeiro, um teólogo anglicano falecido em 2012, vítima de assassinato cruel pelo próprio filho adotivo, foi um dos primeiros autores a aproximar o tema direito e política na literatura protestante brasileira, cuja obra de maior destaque é Cristianismo e política, de 1985. O segundo é um antropólogo, sociólogo e professor catedrático na Balsillie School of International Affairs e na Wilfrid Laurier University, em Waterloo, em Ontário, no Canadá, e professor colaborador na Pós-Graduação em Sociologia da Universidade Federal de São Carlos (UFSCar), autor de grande referência no tema e articulista. Vale citar sua obra de maior vulto: Marxismo e fé cristã, de 1989. 
o tema do direito e da religião. O caso de maior visibilidade ocorreu entre Larry Flynt, editor de uma revista para adultos, e Jerry Falwell, um pastor fundamentalista norte-americano. Em 1996, o caso tornou-se tema do filme O povo contra Larry Flynt, dirigido por Milos Forman. Machado (2013) apresenta casos inclusive apelados ao Tribunal Europeu de Direitos Humanos e ao Conselho Europeu de Direitos Humanos ${ }^{8}$.

Não é diferente na história republicana do Brasil.

O presidente da República dos Estados Unidos do Brasil entre 1919 a 1922, Epitácio Lindolfo da Silva Pessoa, paraibano, que também fora, entre outras nobres e destacadas funções, ministro do Supremo Tribunal Federal, idealizou a construção da famosa estátua do Cristo Redentor, no Rio de Janeiro, Capital Federal do país de então. A matéria é digna de nota aqui, pois, do que ficou para história, constam vários processos, consultas e até mesmo impasses e entraves nos níveis de decisão e planejamento da portentosa obra, planejamento esse iniciado por Pessoa em 1920. Mas não apenas isso, pois constam igualmente, nos anais da história, inúmeras ações judiciais posteriores à inauguração do grande monumento, que ocorreu às $19 \mathrm{~h} 15$ do dia 12 de outubro ${ }^{9}$ de 1931 quando um botão foi acionado de Roma para acender as luzes do Cristo Redentor no Rio de Janeiro.

A nota de maior importância dá conta da consulta feita pelo presidente Pessoa ao consultor-geral da República, o Dr. Rodrigo Octavio, natural de Campinas, São Paulo, que também foi ministro do Supremo Tribunal Federal e um dos membros fundadores da Academia Brasileira de Letras. O presidente Pessoa queria saber se a construção de um monumento como o Cristo Redentor feriria ou não a laicidade do Estado brasileiro, recém-estabelecida na Constituição Federal de 1891. A resposta do consultor Rodrigo Octavio foi no sentido de desaconselhar a construção do referido monumento, pois feriria, sim, o princípio da laicidade. Entre outros aspectos, no parecer de Otávio constava o seguinte: “Considerado o Cristo como símbolo religioso não pode o poder público deferir o pedido para sua colocação num logradouro, que é bem público e, como tal, de uso comum do povo e inalienável (Código Civil, art. 66, nº I, e 67). O Estado é leigo"10.

8 Para pesquisa posterior sobre esses casos, consultar: Kokinakis v Greece; Otto Preminger v Áustria; Cha'are shalom ve tsedek v France; Leyla Sahin v Turkey; Igreja Metropolitana Bessarabia v Moldávia; Patuel C. v France; Laustsi v Italy; Obst v Germany; Schuth v Germany.

9 Em 30 de junho de 1980, o presidente da República João Figueiredo sancionou a Lei do Congresso Nacional que instituiu o dia 12 de outubro como feriado nacional [religioso] brasileiro - Dia da Padroeira do Brasil, Nossa Senhora Aparecida. O art. $1^{\circ}$ da Lei ${ }^{\circ} 6.802$ dessa data diz: "É declarado feriado nacional o dia 12 de outubro, para culto público e oficial a Nossa Senhora Aparecida, Padroeira do Brasil”.

10 Mais informações estão disponíveis em: http://www.paulopes.com.br/2015/05/parecer-de-1921-desaconselha-instalacao-do-cristo-redentor.html\#ixzz4R7zGH9RJ. Acesso em: 15 abr. 2020. 
A história da magistral obra, considerada hoje uma das sete maravilhas do mundo moderno, mostrou que o mandatário desconsiderou totalmente o parecer jurídico apresentado pelo consultor-geral da República, o que ensejou algumas outras ações judiciais envolvendo o mesmo assunto do monumento, como ações sobre quem deveria deter os direitos autorais sobre o Cristo Redentor ou ainda uma ação judicial impetrada em 1940 por um motorista que questionava se a cobrança de ingresso ou de viagens turísticas de acesso exclusivo ao Corcovado não feriria o princípio laico da igualdade religiosa (no que diz respeito ao livre e gratuito acesso).

Estabelece-se assim a necessidade de conhecimento, principalmente por parte dos juristas, de temas afetos à religião. Ações envolvendo temas de feriados nacionais de fundo religioso, pronunciamento sobre criação de novas igrejas ou denominações, uso dos crucifixos em tribunais e reconhecimentos ou não pela Justiça de sentenças eclesiásticas interna corporis são apenas alguns outros exemplos que reafirmam e intensificam o argumento de tal necessidade.

\section{Aspectos especulativos e conceituais de aproximação entre direito e religião}

Após verificar o tema direito e religião sob os enfoques histórico e instrumental supracitados, o presente trabalho deve explorar de forma mais amiúde um terceiro enfoque por ser esse o mais apropriado às pretensões futuras deste autor no estudo do nome de Deus e da suposta quebra do terceiro mandamento nos preâmbulos constitucionais ${ }^{11}$. Trata-se do enfoque especulativo e conceitual de ambos os campos, direito e religião. Essa perspectiva soma-se às duas anteriores (a histórica e a aplicada) e reitera a importância e a relevância do tema no ambiente acadêmico. Adquirir uma visão ampla dos prolegômenos das aproximações entre direito e religião sob esse enfoque especulativo no momento reveste-se, por assim dizer, de especial contribuição para o estudo futuro que este autor pretende empreender.

\footnotetext{
11 A questão-mor que envolve o estudo dos preâmbulos é se eles fazem parte ou não do texto normativo da Constituição. Essa questão será desenvolvida em um artigo próprio em futuro próximo. Todavia, para consulta imediata, vale a leitura da seção "Preâmbulo constitucional" na obra de Moraes (2010). De acordo com autor, o preâmbulo é um documento de intenções e do diploma, e consiste em uma certidão de origem e legitimidade do novo texto. Embora para ele o preâmbulo não faça parte do texto constitucional propriamente dito. Não é, todavia, consenso entre os constitucionalistas esse posicionamento.
} 
Portanto, interessam-nos sobejamente essas aproximações e dessemelhanças conceituais ainda que sob um prisma especulativo, porque o tema do terceiro mandamento está inserido na discussão sobre a origem das leis e do Decálogo, um dos mais antigos e determinantes códigos de leis citados por todos os interessados no assunto. Nossa intenção acadêmica vai muito além de atender meramente às exigências para a obtenção de título. Pretende, sim, acrescentar, de forma técnica, conceitual e definitiva, o estudo do terceiro mandamento nos preâmbulos constitucionais, na esfera acadêmica e de pesquisa, e no campo do direito e religião. Eassim ver acrescentado esse tema como mais um dos elementos de aproximação das duas áreas. Para tal, passemos então a apresentar e desenvolver dois argumentos (textos canônicos e hermenêutica) dos oito sustentados pelo professor Godoy ${ }^{12}$.

Primeiramente, direito e religião se valem de textos canônicos para suas fundamentações doutrinárias ${ }^{13}$.

A palavra cânon significa regra ou "cana de medir", conforme seu sentido original. Um texto canônico, portanto, é aquele que é convencionado e instituído por alguma autoridade (assembleia, grupo, pessoa ou tradição) a servir como modelo ou referência para as demais consultas ou elaborações de textos de interesse de determinada matéria contida nos originais. No caso do cristianismo, o cânon bíblico do Antigo e Novo Testamentos tem datas e critérios distintos na sua formação. E essa diferenciação não está apenas no âmbito dos dois testamentos, mas também na diferença entre o cânon católico(73 livros) e o protestante (66 livros). Apesar de ser um estudo amplo e tenso em alguns momentos da história, ambos, católicos e protestantes, têm cristalizado o uso do Bíblia Sagrada como o principal texto de referência para suas regras de fé e prática. Os concílios eclesiásticos que são os responsáveis pela decretação do texto como canônico no âmbito da religião já haviam, até o quarto século da era cristã, estabelecido e "fechado" o cânon.

Já no âmbito secular do direito, a produção de obras de referência é absurdamente mais dinâmica e passível de revisão e reestruturação do que no âmbito da religião, haja

12 Além dos argumentos do uso de textos canônicos e da ciência hermenêutica por ambos, direito e religião, o Dr. Godoy apresenta outros seis argumentos que aproximam os dois saberes. São eles: a noção de hierarquia; a produção de comentários exegéticos; a ética, posto que o pano de fundo do Estado Constitucional é de matriz judaico-cristã; a teoria do pacto; textos bíblicos na justiça contemporânea, sob a ótica de Régis de Oliveira em sua obra O Direito na Bíblia, de 2010; e o tema do julgamento de Cristo que deu ensejo à obra A crucificação e a democracia, de Gustavo Zagrebelsky, de 2000.

13 Faço uso dessa palavra ressaltando que, embora utilizada com fortíssima importância e frequência por ambos, direito e religião se valem da palavra "doutrina” a partir de prismas epistemológicos distintos. Elucidam o assunto Carson (1992) e Hessen (1987). 
vista a promulgação de leis, decretos, tratados ou declarações e até mesmo de constituições federais elaborados sempre que a autoridade competente julgou necessário. Dessa forma, mesmo sendo sólida a obra referenciada, isso não significa que ela deva ser necessariamente antiga. Aqui estaria uma dessemelhança entre o direito e a religião dentro desse quesito de aproximação. A Constituição Federal brasileira em vigor, por exemplo, possui apenas 32 anos de sua promulgação. Ou ainda, pondere-se sobre o fato de existirem na história brasileira sete constituições ao longo de sua jornada, e isso em menos de 200 anos de distância entre a primeira, de 1824, e a última, de 1988.

Já no ambiente religioso, as discussões canônicas mais recentes remontam ao século XVI no mundo pós-Reforma Protestante. É bem verdade que não se pode falar de cânon bíblico sem citar a descoberta, em 1947, nas cavernas de Qumran, em Israel, dos manuscritos do Mar Morto. Apesar da falta de questionamentos sobre o cânon, com a descoberta foram achados fragmentos de vários livros do Antigo Testamento, excetuando apenas três, além de alguns textos apócrifos. Os textos descobertos são os fragmentos mais antigos encontrados até os dias de hoje, até mesmo mais antigos que os manuscritos utilizados no fechamento do cânon do Antigo Testamento. Portanto, embora seja uma descoberta recente, ela só fez reiterar a antiguidade dos escritos bíblicos.

O jurista faz uso dos textos originários que são as constituições. A autoridade competente para produzi-la e referendá-la é o Congresso Nacional reunido em Assembleia Nacional Constituinte. A semelhança entre os dois campos, direito e religião, é, portanto, que ambos se valem dos textos canônicos como textos de referência. Pode haver mais de um texto de referência, porém não há possibilidade de alterar o texto original.

No dizer do professor Godoy em sua palestra anteriormente citada, "os textos constitucionais são consultados pelos juristas tal como as Escrituras sagradas o são pelos religiosos que a consideram".

As constituições federais brasileiras são diplomas legais de referência para qualquer pesquisador na área do direito e principal objeto de estudo do direito constitucional.

Há os primórdios das constituições como a Carta Magna do rei João Sem Terra, de 1215, que é considerada a grande relíquia para todos os que amam o estudo do direito e das constituições. Há a Constituição espanhola de Cades, tida como base das constituições democráticas.

No Brasil, as sete constituições promulgadas da história dão ensejo a essa tarefa da referência por parte do estudioso do direito. A de 1824, chamada de Constituição do 
Império, já citada anteriormente, carrega em seu texto forte apelo à religião oficial, a religião cristã católica apostólica romana. É a única Constituição brasileira a assegurar uma ideia de religião de Estado ou de Estado religioso. No seu preâmbulo extremamente curto, lê-se: “EM NOMEDA SANTÍSSIMA TRINDADE”; a de 1891, conhecida como tendo recebido fortes contribuições de Rui Barbosa, instituiu o Estado laico, e, nessa perspectiva, é suprimida qualquer referência ao nome de Deus no seu texto.

Na Constituição de 1934, para a qual a influência maior foi de Getúlio Vargas, retoma-se o nome de Deus na expressão: "pondo a confiança em Deus", mas, o mesmo Getúlio, depois de assumir novo mandato e com seus ideais autoritários e totalitários mais expostos e determinantes, promulga em 1937 a chamada Constituição Polaca. Em razão dos ideais cada vez mais totalitários ali exarados, não caberia utilizar o nome de Deus no preâmbulo ${ }^{14}$; foi retomada a tradição de se manter o nome de Deus no preâmbulo na Constituição de 1946, todavia ela surge com um chamado à liberdade religiosa e de expressão artística. Em seu art. 67, lê-se que "as crenças e as artes são livres"; as duas constituições mais recentes (1960 e 1988) mantiveram o nome de Deus nos preâmbulos.

Três outros aspectos de aproximação entre direito e religião se depreendem do uso de textos canônicos: o tema da hermenêutica do texto original, o tema da morte do autor e ainda o conteúdo ético dos textos de referência que, em linhas gerais, são voltados para a prática da justiça do bem e do direito. Nesses três aspectos, direito e religião se assemelham e em alguns casos até se completam.

Direito e religião deparam-se a todo tempo com o chamado problema hermenêutico. Saber qual é exatamente o significado do que se apresenta no texto é a sua missão. A distância cronológica entre o leitor e o autor impõe-se como severa obrigação de submeter o leitor às regras e tarefas da hermenêutica. Tavares (2011) oferece uma definição de hermenêutica do Direito:

\footnotetext{
A Interpretação do Direito é a operação intelectiva por meio da qual a partir da linguagem vertida em disposições (enunciados) com força normativa o operador do Direito chega a determinado e específico conteúdo, sentido e objetivo desse enunciado em face de um caso concreto (real ou hipotético).
}

14 Essa é a conclusão de Vieira (2014). 
Dois autores religiosos compuseram obra de referência sobre o tema da hermenêutica; e é possível perceber que o problema e as preocupações desses teólogos são os mesmos de um jurista quando se vê diante de algum impasse na interpretação das leis.

O alvo da boa interpretação é chegar ao "sentido claro do texto". Eo ingrediente mais importante que a pessoa traz a essa tarefa é o bom-senso aguçado. O teste de uma boa interpretação é onde se expõe o sentido do texto. A interpretação correta, portanto, traz alívio à mente bem como uma aguilhoada ou uma cutucada no coração (FEE; STUART, 1982, p. 14).

Quando mais adiante este autor estiver a aprofundar o tema do terceiro mandamento, ele se deparará com temas inexoravelmente afetos ao campo da hermenêutica, quais sejam: a origem das leis na perspectiva judaica; o conceito de aliança ou pacto; a aplicação das leis do Antigo Testamento para o leitor do Novo Testamento; o que se perdeu e o que não se perdeu em termos de observação válida de algum mandamento da lei ${ }^{15}$; os tipos de lei e a sua correta interpretação: leis apodíticas, leis casuísticas, leis civis, leis cerimoniais, leis éticas e assim por diante. Conforme expressam Fee e Stuart (1982, p. 139): “O problema mais difícil para a maioria dos cristãos no que diz respeito a estes mandamentos é o problema hermenêutico. Como estas formulações legais se aplicam a nós, ou será que não se aplicam?”. Sendo assim, esse campo de semelhança entre o direito e a religião pode ser ainda objeto de mais extensas explorações.

\section{Conclusão}

Falou-se sobre a aproximação entre religião e direito nos termos do que foi estabelecido neste estudo. Direito e religião são aproximados a partir de critérios históricos, critérios práticos de aplicação na jurisprudência brasileira e com critérios especulativos sobretudo em dois campos comuns, a saber: o uso de textos canônicos e a tarefa hermenêutica na resolução de impasses ou conflitos de interpretação. Podemos agora, por assim dizer, tratar do tema do terceiro mandamento e dos preâmbulos constitucionais com maior propriedade, como se o solo já estivesse arado para a semeadura no tempo certo. Doravante, procurar-se-á tratar da seguinte questão:

15 São mais de 600 mandamentos exarados no Pentateuco (livro da Lei de Moisés). Mais especificamente desde o livro de Êxodo, no capítulo 20 até, o de Deuteronômio, no capítulo 33, passando por todo o livro de Levítico e de Números. 
- A partir do estudo dos preâmbulos de constituições políticas, o uso do nome de Deus refere-se apenas a uma afirmação de identidade religiosa ou o terceiro mandamento, na compreensão da tradição judaico-cristã e a partir de sua cosmovisão, é quebrado quando "Deus" é mencionado nesses preâmbulos constitucionais?

A grande contribuição do presente texto, no entanto, foi, independentemente dos resultados das pesquisas futuras, provar que o seu assunto é absolutamente pertinente ao campo de aproximação entre direito e religião e que essa discussão acadêmica deve, portanto, ser acrescentada aos argumentos que defendem a semelhança e/ou dessemelhança do direito com a religião ${ }^{16}$.

Além disso, os argumentos hermenêuticos e canônicos deverão servir de instrumentos principais no estudo que se pretende mais à frente. É por essa razão que concluímos com a certeza de que os objetivos deste artigo foram cabalmente cumpridos.

\section{REFERÊNCIAS}

A BÍBLIA Sagrada. Tradução João Ferreira de Almeida. Versão Revista e Atualizada, 2. ed. Barueri: Sociedade Bíblica do Brasil, 1993.

ALMEIDA, M. C. A religião na caserna: o papel do capelão militar. 2006. Dissertação (Mestrado em Teologia) - Universidade Presbiteriana Mackenzie, São Paulo, 2006.

BRASIL. Carta da Lei de 25 de março de 1824. Manda observar a Constituição Politica do Imperio, offerecida e jurada por Sua Magestade o Imperador. Disponível em: https://www.planalto.gov.br/ccivil_03/constituicao/constituicao24.htm. Acesso em: 25 ago. 2020.

CARSON, D. A. A exegese e suas falácias: perigos na interpretação da Bíblia. Tradução Valéria Fontana. São Paulo: Edições Vida Nova, 1992.

CAVALCANTI, R. Cristianismo e Política. Teoria bíblica e prática histórica. Viçosa: Ed Ultimato, 2002.

FEE, D. G.; STUART, D. Entendes o que lês? Um guia para entender a Bíblia com o auxílio da exegese e da hermenêutica. Tradução Gordon Chown. São Paulo: Edições Vida Nova, 1982.

FEILER, B. Abraão: uma jornada ao coração de três religiões. São Paulo: Sextante, 1998.

FERRAZ JUNIOR, T. S. Introdução ao estudo do direito: técnica, decisão, dominação. 7. ed. São Paulo: Atlas, 2012.

16 No início do primeiro módulo do curso de Pós-Graduação em Estado Constitucional e Liberdade Religiosa, o coordenador do curso motivou todos os alunos a trabalhar em seus papers os temas que seriam tratados na monografia de conclusão do curso. E desde o primeiro paper, este autor já persegue, sob a orientação do Dr. Arnaldo Godoy, o tema do uso do nome de Deus nas constituições, visando contribuir para a comunidade acadêmica com essa aproximação entre direito e religião. O tema do primeiro trabalho foi “O NOME DE DEUS NOS PRÊMBULOS CONSTITUCIONAIS: Do direito comparado à suposta quebra do terceiro mandamento”. 
- MARCELO COELHO ALMEIDA

FRESTON, P. (org.). Marxismo e Fé Cristã: O Desafio Mútuo. São Paulo: ABU Editora, 1989.

HESSEN, J.Teoria do conhecimento. Tradução Antônio Correia. 8. ed. Coimbra: Arménio Amado, 1987.

MACEDO, J. C. Capelania evangélica militar no Corpo de Bombeiros do Estado do Rio de Janeiro. Rio de Janeiro: [s. n.], 1994.

MACHADO, J. E. M. Estado constitucional e neutralidade religiosa: entre o teísmo e o (neo)ateísmo. Porto Alegre: Livraria do Advogado, 2013.

MORAES, A. de. Direito Constitucional. 26. ed. São Paulo: Atlas, 2010.

OLIVEIRA, R. F. de. O Direito na Bíblia. Uruguaiana: Editora Conceito, 2010.

PARECER de 1921 desaconselhou instalação do Cristo Redentor. Paulopes, 28 maio 2015. Disponível em: https://www.paulopes.com.br/2015/05/parecer-de-1921-desaconselha-instalacao-do-cristo-redentor.html\#ixzz4R7zGH9RJ. Acesso em: 25 ago. 2020.

TAVARES, A. R. Curso de direito constitucional. 9. ed. São Paulo: Saraiva, 2011.

VIEIRA, T. Sob a proteção de Deus: natureza jurídica do Preâmbulo Constitucional - Capítulo 7. In: SANTANA, U.; MORENO, J.; TAMELINI, R. (org.). O direito de liberdade religiosa no Brasil e no mundo: aspectos teóricos e práticos para especialistas e líderes religiosos em geral. São Paulo: Associação Nacional dos Juristas Evangélicos, 2014. p. 109-120.

ZAGREBELSKY, G. A crucificação e a democracia. São Paulo: Ed. Saraiva. 2000. 